\title{
Intracellular Calcium Levels during the Period of Delayed Excitotoxicity
}

\author{
Janet M. Dubinsky \\ Department of Physiology, University of Texas Health Science Center, San Antonio, Texas 78284-7756
}

\begin{abstract}
Intracellular calcium concentrations $\left(\left[\mathrm{Ca}^{2+}\right]_{i}\right)$ among cultured hippocampal neurons were monitored during and in the hours following an excitotoxic glutamate application to determine the time course of changes involved in delayed excitotoxicity. After a 5 min toxic insult, $\left[\mathrm{Ca}^{2+}\right]_{i}$ increased immediately and remained elevated for an hour. Subsequently, $\left[\mathrm{Ca}^{2+}\right]_{i}$ declined to normal resting levels and remained so up to $13 \mathrm{hr}$ following insult. Only a few neurons displayed greatly elevated $\left[\mathrm{Ca}^{2+}\right]_{;}$at these extended times. Survival experiments in sister cultures indicated that $85 \%$ of the neurons died after $24 \mathrm{hr}$. Therefore, intracellular calcium returned to baseline levels prior to neuronal death. Additionally, during this period when basal calcium levels had recovered, the majority of neurons responded to a second excitatory amino acid application with a second increase in $\left[\mathrm{Ca}^{2+}\right]_{i}$.
\end{abstract}

[Key words: excitotoxicity, glutamate, intracellular calcium, neuronal cell death, neurotoxicity, hippocampal neurons]

Elevations in intracellular calcium levels have been implicated in the process of cellular injury and death, among both neuronal cells and other cell types. Among neurons both in vivo and in vitro, overstimulation of glutamate (GLU) receptors leads to a progressive cell loss. Removal of extracellular calcium or blockade of the NMDA subtype of GLU receptors can prevent this excitotoxicity (Garthwaite and Garthwaite, 1986; Hartley and Choi, 1989; Manev et al., 1989). Transient activation of the NMDA receptors produces a rapid influx of calcium and increase in $\left[\mathrm{Ca}^{2+}\right]_{i}$ (MacDermott et al., 1986; Glaum et al., 1990; Murphy et al., 1987). Prolonged activation of GLU receptors, over a period of minutes, or multiple short applications results in an extended elevation of $\left[\mathrm{Ca}^{2+}\right]_{i}$ (Connor et al., 1988; Glaum et al., 1990; Michaels and Rothman, 1990; Dubinsky and Rothman, 1991). Recovery of initial, baseline calcium levels has been reported for cultured neurons less than $7 \mathrm{~d}$ in vitro (Wahl et al., 1989). Otherwise, only partial, slow recoveries to plateau levels have been noted during the limited experimental time scale (Connor et al., 1988; Ogura et al., 1988; Manev et al., 1989; Glaum et al., 1990; Ciardo and Meldolesi, 1991). An assumed

\footnotetext{
Rcceived Apr. 23, 1992; revised July 29, 1992; accepted Aug. 3, 1992,

I thank Dr. Thomas C. Smith for helpful discussions, Dr. Cheng Yuan for statistical consultation, Ms. Julie Hendrikson and Mr. John Burner for technical assistance, and Ms. Marta Fournier for preparation of the tissue cultures. This work was supported by NIH Grant AG10034.

Correspondence should be addressed to Janet M. Dubinsky, Ph.D., Department of Physiology, University of Texas Health Science Center, 7703 Floyd Curl Drive, San Antonio, TX 78284-7756.
}

Copyright (C) 1993 Society for Neuroscience $0270-6474 / 93 / 130623-09 \$ 05.00 / 0$ lack of total recovery and the subsequent, sustained $\left[\mathrm{Ca}^{2+}\right]_{i}$ elevations have been implicated in the eventual neuronal death (Ogura et al., 1988; Wahl et al., 1989; Manev et al., 1989; Glaum et al., 1990; Ciardo and Meldolesi, 1991).

Typically in these experiments, calcium levels are monitored for periods of $15 \mathrm{~min}$ to $1 \mathrm{hr}$ following receptor stimulation (Ogura et al., 1988; Manev et al., 1989; Wahl et al., 1989; Glaum et al., 1990; Ciardo and Meldolesi, 1991). Beyond that time, cellular sequestering and extrusion of the calcium-sensitive dye fura-2 are thought to alter the accuracy of the measurements (Di Virgilio et al., 1990). Yet neuronal death does not occur immediately, but rather during the subsequent 18-24 hr period (Rothman et al., 1987; Hartley and Choi, 1989; Siesjo, 1989; Koh et al., 1990). The behavior of $\left[\mathrm{Ca}^{2+}\right]_{i}$ in this intermediate time period is unknown. Therefore, cytoplasmic calcium concentrations were examined up to $13 \mathrm{hr}$ following GLU receptor stimulation. In the experiments reported here, $\left[\mathrm{Ca}^{2+}\right]_{i}$ returned to prestimulation baseline levels in the second hour following toxic exposure. Furthermore, many neurons that had previously experienced an insult could respond a second time to GLU application.

\section{Materials and Methods}

Tissue culture. Hippocampal neurons were dissociated from 1-d-old neonatal rat pups (Harlan) according to published procedures (Dubinsky, 1989; Yamada et al., 1989). Briefly, hippocampi were removed, minced, and incubated for $20 \mathrm{~min}$ at $37^{\circ} \mathrm{C}$ in $\mathrm{L}-15$ containing $3 \mathrm{mg} / \mathrm{ml}$ papain (Sigma) and $3 \mathrm{mg} / \mathrm{ml}$ bovine serum albumin (BSA). After gentle trituration in growing medium, the cell suspension was layered on L-15 containing $100 \mathrm{mg} / \mathrm{ml} \mathrm{BSA}$ and centrifuged at $500 \mathrm{rpm}$ for $5 \mathrm{~min}$. The pellet was resuspended in growing medium [minimum essential medium (MEM) without glutamine containing $27.75 \mathrm{~mm}$ glucose, $10 \%$ NuSerum (Collaborative Research), $50 \mathrm{U} / \mathrm{ml}$ penicillin, and $50 \mu \mathrm{g} / \mathrm{ml}$ streptomycin, $335 \mathrm{mOsm}$ ], and 500,000 -cell aliquots were added to $35 \mathrm{~mm}$ Petri dishes preplated with cortical astroglial cells. Plating density was the same for all toxicity and calcium measurement experiments. Plastic Petri dishes coated with polylysine were used for the toxicity experiments; collagen-and polylysine-coated glass-bottomed Petri dishes were used for the calcium measurements. Fluorodeoxyuridine $(15 \mu \mathrm{g} / \mathrm{ml})$ and uridine $(35 \mu \mathrm{g} / \mathrm{ml})$ were added $24 \mathrm{hr}$ after plating to restrict glial overgrowth. The astroglial feeder layer was passaged from flasks plated once a month (Dubinsky, 1989). Cultures were maintained at $37^{\circ} \mathrm{C}$ in a humidified atmosphere containing $5 \% \mathrm{CO}_{2}$ for $12-18 \mathrm{~d}$ before use.

Toxicity. After 12-14 d in culture, when neurons had developed an extensive network of processes and evoked synaptic activity can be recorded (Yamada et al., 1989; Yoon and Rothman, 1991), two healthy fields per dish were preselected and marked for relocation with fiducial marks (1) matching the Petri dish to the inverted phase-contrast microscope and (2) identifying fields on the underside of the dish. Fields were chosen with a plentiful, even distribution of healthy, phase-bright hippocampal neurons. Fields with dense clumps of neurons were avoided since superimposed live and dead cells were difficult to distinguish accurately. The growing medium was replaced by $1.5 \mathrm{ml}$ of MEM containing (in mM) 27.75 glucose, 35 sucrose, 0.01 glycine, and $10 \mathrm{Na}$ HEPES (336 mOsm). A $15 \mu \mathrm{l}$ aliquot of $50 \mathrm{~mm} \mathrm{Na}$-glutamate was added 


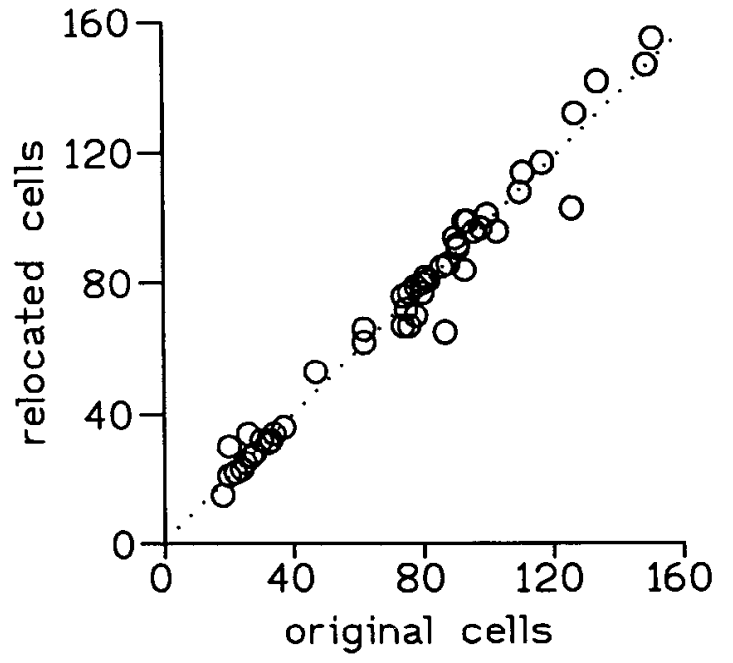

Figure 1. Accuracy of relocation and cell counting procedure. Abscissa represents cell counts of neuronal cell bodies in selected fields prior to toxic exposure. Ordinate represents the sum of all cells counted in the relocated fields (live + dead). Broken line is a linear regression through all 52 data points. Slope $=0.976 \pm 0.023$ (mean \pm SEM), which was not significantly different from 1.0 (two-tailed $t$ test). Data were taken from selected fields in three separate experiments performed over a 6 month period. In some of these experiments, cell plating density was intentionally altered (250,000-1,000,000 cells per Petri dish) to ensure that counting and survival remained consistent in the event of inadvertent discrepancies in plating densities.

to the edge of the dish followed by gentle mixing to bring the final GLU concentration to $500 \mu \mathrm{M}$ except as noted. After a 5 min incubation, cultures were rinsed once with Earle's Balanced Salt Solution (EBSS I) containing (in mM) $116 \mathrm{NaCl}, 5.4 \mathrm{KCl}, 1.8 \mathrm{CaCl}_{2}, 0.1 \mathrm{MgSO}_{4}, 0.9$ $\mathrm{NaH}_{2} \mathrm{PO}_{4}, 26.2 \mathrm{NaHCO}_{3}, 27.75$ glucose, 35 sucrose, 0.01 glycine, and phenol red $(328 \mathrm{mOsm})$, and incubated at $37^{\circ} \mathrm{C}$ in $5 \% \mathrm{CO}_{2}$. Additional rinses progressively detached neurons from the glial feeder layer, producing unreliable counts and were therefore not performed.

At various times after GLU exposure, individual Petri dishes were removed from the incubator. Trypan blue dye was added for a final concentration of $0.12 \mathrm{mg} / \mathrm{ml}$, and cells containing and excluding dye were counted in the relocated fields (Finkbeiner and Stevens, 1988; Michaels and Rothman, 1990). Cell counts, obtained with a $10 \times$ objective, were generally obtained only after the toxic exposure. Periodically, fields were counted both initially and again at $24 \mathrm{hr}$ to ensure accurate relocation. Figure 1 demonstrates that the fate of nearly all of the neurons originally chosen could be determined in this manncr. The average number of neurons per field in these experiments was $103.8 \pm$ 39.7 (mean $\pm \mathrm{SD} ; N=56$ ).

Calcium measurements. Intracellular calcium levels were assessed by ratio measurements of the calcium indicator dye fura-2 (Grynkiewicz et al., 1985). Cultures were loaded with the dye by addition of $4 \mu \mathrm{M}$ of the acetylmethyl ester of fura-2 (fura-2-AM) in their current medium at $37^{\circ} \mathrm{C}$. For imaging of initial responses, fura-2-AM was added to the growing medium. For imaging of basal calcium levels and responses following a previous toxic GLU exposure, fura-2-AM was added to the EBSS +. After $15 \mathrm{~min}$, dishes were rinsed once with EBSS + and returned to the incubator for $15-45 \mathrm{~min}$. Prior to fluorescence imaging, the EBSS+ was replaced with a basic salt solution containing (in mM) $139 \mathrm{NaCl}, 3$ $\mathrm{KCl}, 1.8 \mathrm{CaCl}_{2}, 0.8 \mathrm{MgSO}_{4}, 1.0 \mathrm{NaHCO}_{3}, 27.75$ glucose, 15 sucrose, $10 \mathrm{Na}-\mathrm{HEPES}$, and 0.01 glycine (329 mOsm).

Dishes were placed on the heated stage $\left(33^{\circ} \mathrm{C}\right)$ of a Nikon inverted microscope equipped with an $100 \mathrm{~W} \mathrm{Hg}$ fluorescence lamp, an Olympus $40 \times, 1.0$ NA oil epifluorescence objective, a $410 \mathrm{~nm}$ dichroic mirror, a 520 high-pass emission filter, and a computer-controlled shutter and filter wheel with $340 \mathrm{~nm}$ and $380 \mathrm{~nm}$ excitation filters. A Videoscope intensifier tube and $\mathrm{CoHu} \mathrm{CCD}$ camera captured the fluorescence emission and sent the signal for digitization to a Perceptics, Inc., image processing system. Ratio measurements were calculated according to the method of Grynkiewicz et al. (1985). By the end of each experiment, prolonged exposure to excitatory amino acids (EAAs) often left hippocampal neurons swollen, precluding measurement of calibration values on monitored cells. Thus, all values are reported as raw fluorescence ratios $(340: 380)$. Values for the maximum ratio obtained with saturating calcium concentrations $\left(R_{\max }=14.9\right)$, the minimum ratio value in the absence of fura-2-calcium binding $\left(R_{\min }=0.10\right)$, and a scale factor based on the fluorescence emission at $380 \mathrm{~nm}$ with zero calcium bound divided by the emission in saturating calcium $(\beta=10.1)$ were obtained in ionomycin- and EGTA-treated separate cultures. Assuming a $K_{D}$ of 224 nM (Grynkiewicz et al., 1985), ratios of $0.4,1.0$, and 2.5 corresponded to $\left[\mathrm{Ca}^{2+}\right]$ of 47,146 , and $438 \mathrm{nM}$, respectively. Autofluorescence of hippocampal neurons in the absence of any dye could not be detected at the image intensifier gains employed to measure fura- 2 emissions.

While ratio measurements were being obtained, various EAA receptor agonists were applied by addition of an aliquot of $100 \times$ stock solution followed by gentle mixing. While this procedure did not produce an instantaneous, uniform concentration jump, as might be possible with various rapid-perfusion systems, it did mimic the toxic application exactly. In one set of experiments limiting GLU exposure to $5 \mathrm{~min}$, the dish was rinsed once, as in the toxicity experiments, while on the microscope stage. Otherwise, EAAs were not removed during subsequent ratio measurements.

Calcium measurements after toxic exposure. In experiments where calcium measurements were made after previous excitotoxic exposure to GLU, cultures grown on glass-bottom dishes were exposed to 500 $\mu \mathrm{M}$ GLU according to the procedure described for toxicity experiments. After being returned to the incubator for a variable time, they were loaded with fura-2-AM as described above. After acquiring ratio values indicative of the resting $\left[\mathrm{Ca}^{2+}\right]_{i}$, a second dose of an EAA was applied to the culture from a $100 \times$ stock solution with mixing. Note that cultures were only monitored during a single EAA exposure. Sequential observations of the same culture during two toxic insults were avoided because fura- 2 became sequestered into mitochondria after several hours and latent phototoxicity from fluorescence exposure might alter the processes being monitored.

Intracellular concentration of fura-2. With the fura-2-AM loading procedure, care must be taken not to allow the neurons to accumulate too much fura-2. Overly high concentrations can cause inner filter effects or perhaps begin actually to buffer intracellular calcium (Moore et al., 1990). If this were the case, the prolonged elevation of [ $\left.\mathrm{Ca}^{2}\right]_{i}$ after GLU exposure might be attributable to competition between fura- 2 buffering and normal intracellular processes. Therefore, fura-2-AM exposure was limited to $15 \mathrm{~min}$. Estimates of the intracellular concentration of fura-2 were made according to the method of Moore et al. (1990). Known concentrations of pentapotassium fura- 2 were prepared in both lowand high-calcium calibration solutions. Blunt tip micropipettes were filled with these solutions, and their contents were expelled by pressure under oil previously saturated with non-dye-containing salt solution. In this way, cell-sized spherical, fluorescent droplets could be imaged containing a known quantity of dye. The fluorescence intensity of the droplets $\left(\mathrm{FI}_{\mathrm{dr}}\right)$ for $100 \mu \mathrm{M}$ fura-2, the recommended level, was calculated as the sum of the 340 fluorescence plus a weighting factor multiplied by the $380 \mathrm{~nm}$ measurement (Moore et al., 1990). Fluorescence intensities for fura-2-AM-loaded hippocampal cells $\left(\mathrm{FI}_{\text {ccll }}\right)$ were similarly computed. The weighting factor was calculated as the change in fluorescence at $340 \mathrm{~nm}$ divided by the change in fluorescence at $380 \mathrm{~nm}$ between stimulated and basal conditions. This avoided using previously calculated estimates of $R_{\min }, R_{\max }$, and $\beta$ and allowed each cell to be internally consistent. Cell and droplet volumes were calculated assuming cells were ellipsoids and droplets were spheres. The concentration of fura- 2 in a cell could be calculated from Equation 3 of Moore et al. (1990): cell [fura-2] = droplet [fura-2] * (droplet volume/cell volume $) \cdot\left(\mathrm{FI}_{\mathrm{ccll}} / \mathrm{FI}_{3 \mathrm{ph}}\right)$. The drawback of this method is that fura- 2 concentrations in nonresponding neurons could not be estimated. However, the range of initial fluorescence intensities at $340 \mathrm{~nm}$ and $380 \mathrm{~nm}$ of nonresponding neurons was equivalent to that of responding neurons.

Electrophysiology. Whole-cell patch electrode voltage-clamp recordings were performed at room temperalure with an Axopatch 200 amplifier according to established procedures (Hamill et al., 1981; Dubinsky, 1989). The external solution was identical to that used in the calcium measurements. Internal solution within the patch pipette contained (in mM) $138 \mathrm{~K}$-isethionate, $2 \mathrm{KCl}, 10 \mathrm{Na}$-HEPES, $2 \mathrm{Mg}$-ATP, 28 glucose, and 20 sucrose $(\mathrm{pH} \mathrm{7.2)}$. Blunt tip pipettes were positioned $20-50 \mu \mathrm{m}$ from a neuron for pressure ejection of $100 \mu \mathrm{M}$ GLU. 

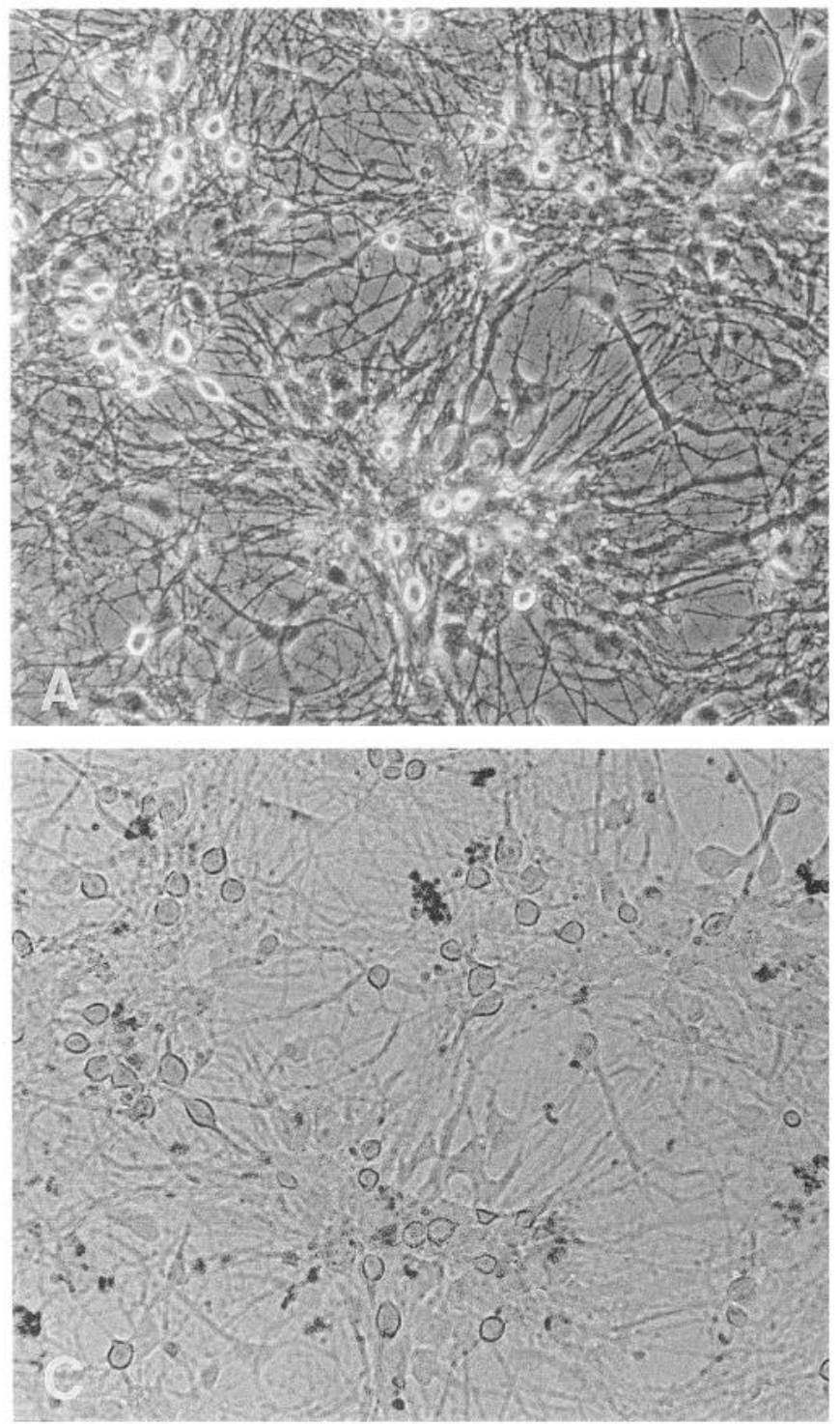
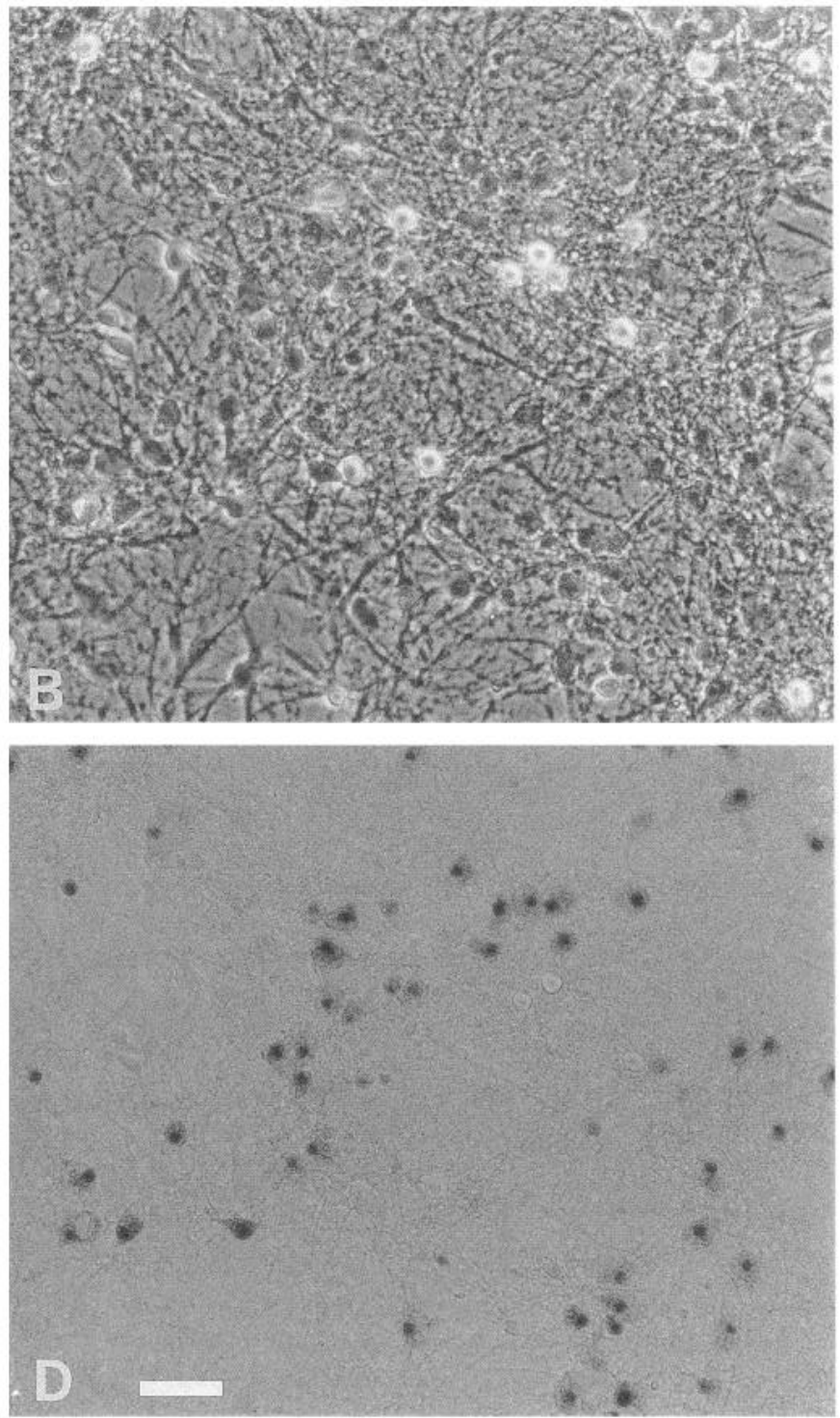

Figure 2. Phase-contrast $(A, B)$ and bright-field $(C, D)$ photomicrographs of hippocampal neurons 24 hr after excitotoxic injury. Neurons un ble to exclude trypan blue do not appear phase bright and are considered dead. $A$ and $C$, Representative field from a culture receiving only solu ion changes as a control. $B$ and $D$, Culture exposed to $500 \mu \mathrm{M}$ GLU for $5 \mathrm{~min}$. Scale bar, $50 \mu \mathrm{m}$.

\section{Results}

Initially, the extent of neuronal death was assessed following a short excitotoxic insult (Fig. 2). When measured in sister cultures from platings used in the calcium measurements, only about $15 \%$ of hippocampal neurons survived GLU exposure compared to $80 \%$ survival among cultures receiving equivalent solution changes without GLU (Fig. 3).

Measurements of intracellular calcium levels were obtained in fura-2-AM-loaded neurons during a $5 \mathrm{~min}$ GLU exposure and subsequent rinse, identical to the toxic paradigm. Upon addition of GLU to the dish, ratio measurements rose and remained elevated following the rinse (Fig. 4A). Approximately $20 \mathrm{~min}$ after the removal of GLU, ratio measurements began to decline slowly, returning to near basal levels.

Intracellular calcium measurements were made at extended times following a similar GLU exposure by loading dishes with fura-2-AM at varying times after the toxic event (Fig. 4B). Pre- vious toxic insult did not appear to affect the ability of surviving neurons to accumulate fura-2-AM (naive neurons, $113 \pm 15$ $\mu \mathrm{M}$ fura- 2 , mean $\pm \mathrm{SEM}, N=58$, vs neurons more than $2 \mathrm{hr}$ after a toxic exposure, $83 \pm 9 \mu \mathrm{M}, N=100$; not significantly different, Satterthwaite's two-tailed $t$ test). Even morphologically compromised neurons with extremely rounded, swollen, and transparent appearances were able to accumulate dye. Within the first hour after GLU exposure, ratio measurements, indicative of $\left[\mathrm{Ca}^{2+}\right]_{i}$, were elevated. However, with increasing elapsed time, initial ratio measurements declined. Ratio measurements in surviving cells $2-13 \mathrm{hr}$ after a toxic exposure indicated that $\left[\mathrm{Ca}^{2+}\right]_{i}$ had returned to near normal intracellular levels. The small elevations in basal calcium levels at 4 and $7 \mathrm{hr}$ were attributable to a few neurons with very high ratios (4 out of 23 neurons at $4 \mathrm{hr}$ and 4 out of 19 neurons at $7 \mathrm{hr}$ ) and therefore do not represent slow oscillations in $\left[\mathrm{Ca}^{2+}\right]_{i}$ among the entire population. Altogether, only 8 out of 148 neurons monitored 2-13 hr after excitotoxic exposure had greatly elevated basal 


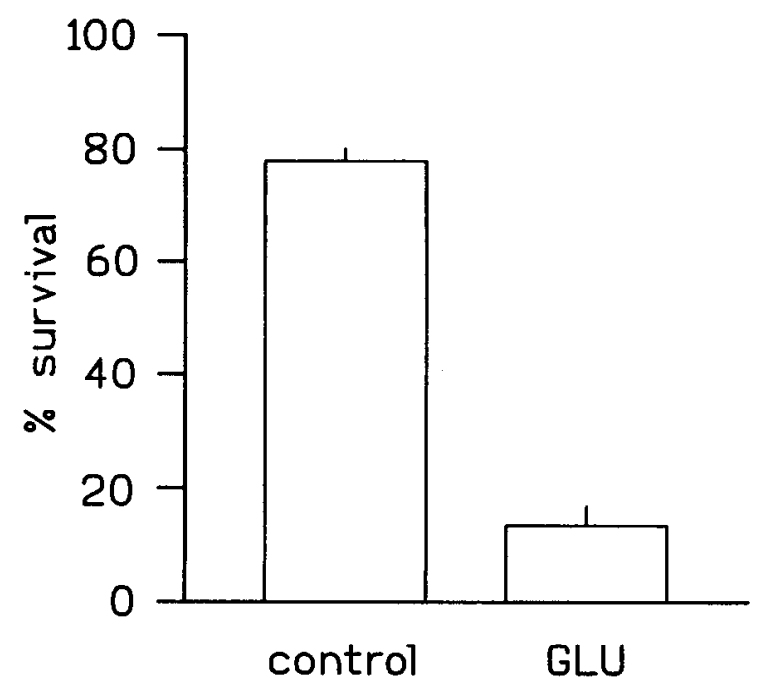

Figure 3. Survival of hippocampal neurons $24 \mathrm{hr}$ after exposure to $300 \mu \mathrm{M}$ GLU or simple solution changes (control). Data were acquired in sister cultures from six platings used in the calcium measurement experiments. Data are mean \pm SEM of cell counts from individual fields: 34 control, 22 GLU.

ratios $(R>1.0)$. This incidence was not significantly different from that encountered among naive cultures (5 out of 129 , Fischer's Exact Test; Steel and Torrie, 1980), but the extent of elevated calcium levels was significantly different between these subpopulations $(p=0.034, R=2.75 \pm 1.58, N=8$ for extended times vs $R=1.28 \pm 0.30, N=5$ initially; Satterthwaite's $t$ test; Steel and Torrie, 1980).

The normal baseline calcium levels recorded several hours aftcr toxic exposure might be explained by the preferential survival of a subpopulation of neurons lacking GLU receptors. To test this, cultures pretreated with toxic GLU exposure were loaded with fura-2-AM and challenged a second time by GLU agonists. The majority of labeled neurons responded to a second EAA application with an increase in $\left[\mathrm{Ca}^{2+}\right]_{i}$ (Fig. 5). Responses to the second EAA application were nearly identical to those of naive cultures to an initial toxic exposure. Responses were generated during the second dose following stimulation of all GLU receptor subtypes by GLU itself (Fig. $5 A$ ) and by stimulation of individual receptor subtypes. Methanoglutamate, a selective NMDA agonist as potent as GLU (Lanthorn et al., 1990), was employed to stimulate the NMDA receptor (Fig. 5B). NMDA produced similar responses. The metabotropic receptor was activated by quisqualate in the presence of MK-801 and 6-cyano7-dinitroquinoxaline-2,3-dione (CNQX) (Fig. 5C; Furuya et al., 1989; Murphy and Miller, 1989). High doses of kainate (500 $\mu \mathrm{M})$, probably activating both NMDA and non-NMDA receptors (Murphy and Miller, 1989b; Michaels and Rothman, 1990), produced responses similar to GLU. The continued presence of GLU, methanoglutamate, and kainate in the bath precluded the appearance of any recovery. The quisqualate response was composed of an initial transient increase followed by a residual plateau (Murphy and Miller, 1989a).

Not all hippocampal neurons responded to GLU receptor agonists with increases in $\left[\mathrm{Ca}^{2+}\right]_{i}$ (Fig. 6). In cultures monitored during the first exposure to GLU, nonresponding neurons, clearly loaded with fura-2, comprised $6.2 \%$ of the sampled population (Table 1). The baseline ratios of nonresponding neurons were not significantly different from the baseline ratios of responding neurons. In cultures pretreated with a toxic dose of
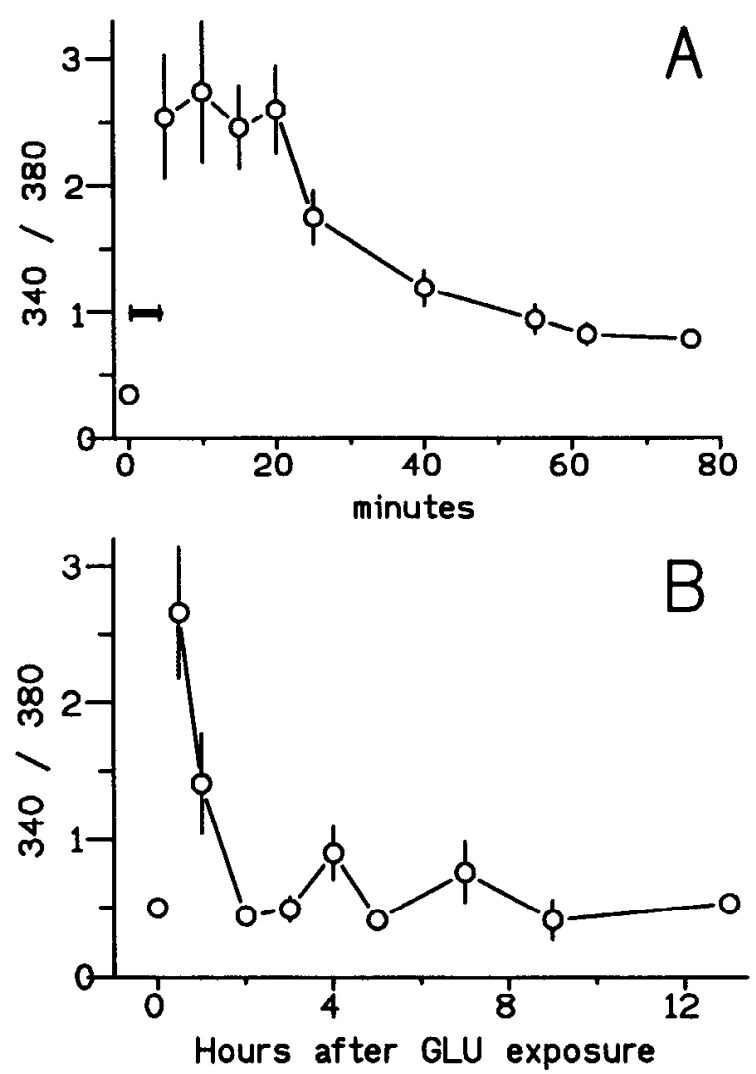

Figure 4. Time course of changes in ratio measurements of fura-2 fluorescence at various times after toxic GLU exposure. $A$, Slow recovery of basal calcium levels in cultures receiving $500 \mu \mathrm{M}$ GLU during the 5 min indicated by the bar. Data are from 16 neurons from a representative experiment. $B$, On a longer time scale, hippocampal cultures were exposed to GLU prior to the ratio measurement. At 0.5 and $1 \mathrm{hr}$, fura2 -AM loading preceded the measurements by $30 \mathrm{~min}$. At all other times, fura-2-AM loading began $1 \mathrm{hr}$ prior to the time indicated on the abscissa. Each data point represents 16-91 cells from two or more experiments, with the exception of eight and nine cells in the single experiments at 9 and $13 \mathrm{hr}$, respectively.

GLU, $24.2 \%$ of the neurons did not respond when GLU receptor agonists were applied after various delays. In the hour following the pretreatment, ratio measurements increased significantly compared to naive cultures, reflecting the short-term increase in $\left[\mathrm{Ca}^{2+}\right]_{i}$ observed in the experiments of Figure $4 A$. At longer time intervals, ratio values returned to levels indistinguishable from initial values in unstimulated neurons. Neurons unable to respond to a second GLU receptor stimulation had, on average, a higher initial ratio measurement than responders, although this distinction was only significantly different during the hour immediately following the first GLU application. Thus, a greatly elevated $\left[\mathrm{Ca}^{2+}\right]_{i}$ may preclude further $\left[\mathrm{Ca}^{2+}\right]_{i}$ increases following a second EAA application, but the absence of a change in $\left[\mathrm{Ca}^{2+}\right]$ did not indicate that the basal calcium levels were already elevated.

All fields selected for ratio imaging contained primarily healthy ncurons with normal morphology as obscrved by phase-contrast microscopy. However, the increased proportion of neurons failing to respond to a second dose of GLU raised the possibility that these might be the subpopulation involved in the immediate act of dying. If so, the nonresponders might be expected to display deteriorating morphology (e.g., neurons designated by the square and triangle in Fig. 6). To investigate this possibility, neurons with corresponding, initial, phase-contrast video 

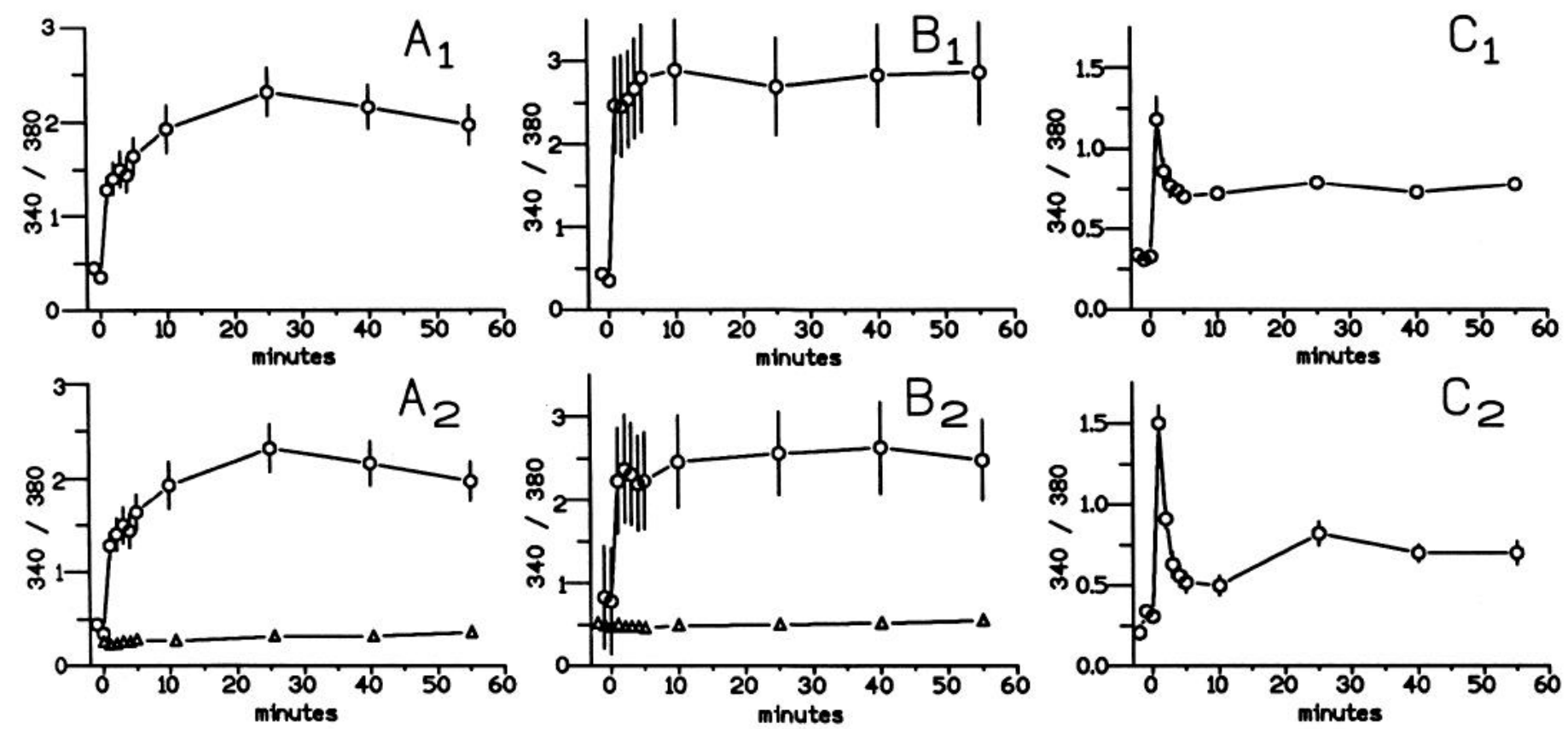

Figure 5. Increases in $\left[\mathrm{Ca}^{2+}\right]_{i}$ in response to first and second EAA applications: $500 \mu \mathrm{M}$ GLU $(A), 100 \mu \mathrm{M}$ methanoglutamate $(B)$, and $500 \mu \mathrm{M}$ quisqualate in the presence of $20 \mu \mathrm{M} \mathrm{CNQX}$ and $20 \mu \mathrm{M} \mathrm{MK}-801(C) . A_{l}-C_{l}$, Initial responses in naive, control cultures. $A_{2}$, Response to a second toxic GLU application (circles) $5 \mathrm{hr}$ after the initial toxic pretreatment. Data are mean $\pm \mathrm{SEM}$ of 35 cells from three experiments. Control responses (triangles) are average of four unstimulated neurons $4 \mathrm{hr}$ after GLU pretreatment. $B_{2}$, Response of NMDA receptors (circles) in nine neurons to application of methanoglutamate $3 \mathrm{hr}$ following pretreatment. Control responses (triangles) are average of $11 \mathrm{neurons,} 3 \mathrm{hr}$ after pretreatment, challenged with methanoglutamate plus $20 \mu \mathrm{M}$ CNQX and $20 \mu \mathrm{M}$ MK-801. $C_{2}$, Response of metabotropic receptors on 14 neurons to quisqualate in the presence of CNQX and MK-801 $3 \mathrm{hr}$ following pretreatment.
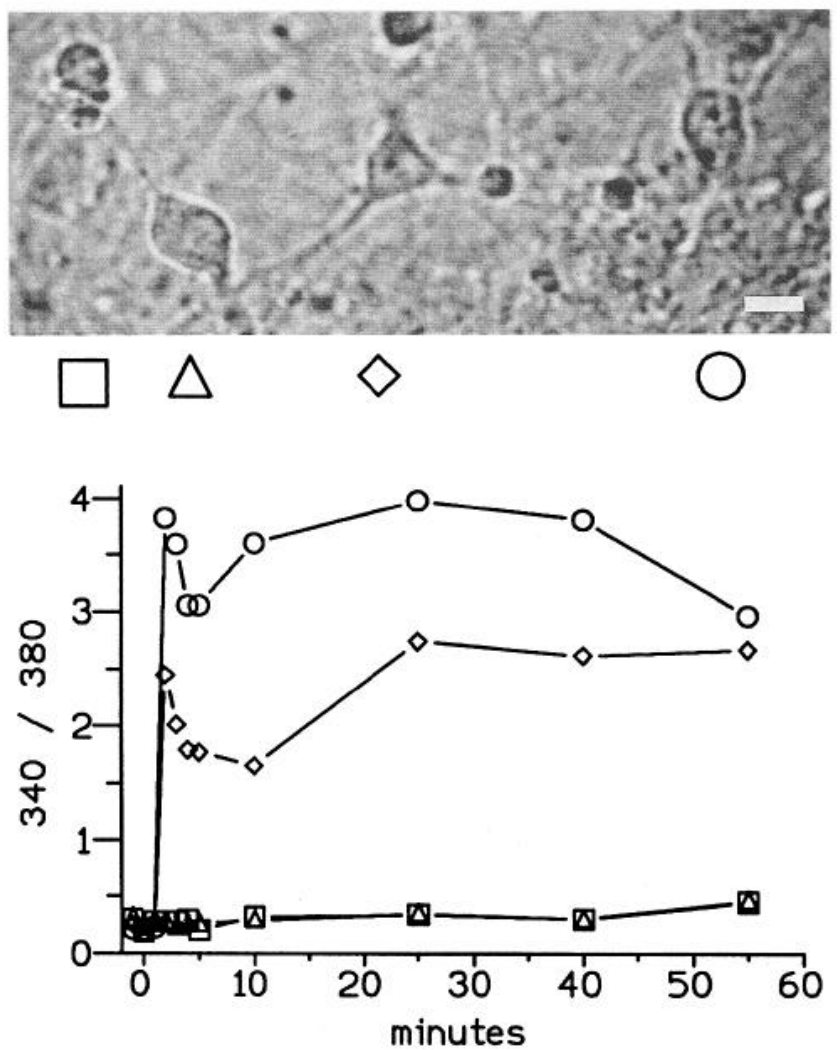

Figure 6. Calcium changes in response to GLU in four neurons $13 \mathrm{hr}$ after toxic insult. Fura-2 ratio measurements are plotted using the symbols underneath each neuron in the video micrograph. Note the very fragmented appearance of one neuron (square) and the swollen form of another with a detached neuritic stump (triangle). The other two neurons images were retrospectively classified by the investigator into two categories according to morphology, good versus compromised, without reference to the calcium values (Table 2). Neurons with compromised morphology displayed one or more of the following criteria: round or distended cell bodies, membrane blebbing, detachment of neurites, or condensed or fragmented somas. Very few neurons with compromised morphology were observed prior to any GLU exposure. In the hour following the GLU pretreatment, some nonresponding neurons appeared swollen. At extended times after GLU pretreatment, neurons with deteriorating morphology became more numerous, especially among those unable to respond to a second toxic insult. A significantly higher percentage of morphologically compromised neurons was encountered at these later times (comparisons made with Fischer's Exact Probability Test). Thus, a morphologically compromised neuron is more likely to be unable to respond to a second toxic insult, but a nonresponsive neuron may not as yet display morphological deterioration.

While the majority of neurons responded to a second toxic dose of EAA, about one-quarter of the population did not, suggesting that a subpopulation may lack GLU receptors. This subpopulation would not be expected to respond to GLU electrophysiologically. To confirm the presence of a GLU-resistent subpopulation, intracellular recordings were made from hippocampal neurons $2-24 \mathrm{hr}$ following a previous excitotoxic exposure. Patch electrodes were successfully sealed to normal or slightly swollen neurons still presenting a white-rimmed, phase-

(circle and diamond) appear phase bright and healthy with intact neurites. Scale bar, $10 \mu \mathrm{m}$. 
TABLE 1. Ratio measurements representing basal calcium levels before toxic GLU application and at various times afterward

\begin{tabular}{llll} 
& No pretreatment & $\begin{array}{l}\leq 1 \mathrm{hr} \text { after } \\
\text { pretreatment }\end{array}$ & $\begin{array}{l}>1 \mathrm{hr} \text { after } \\
\text { pretreatment }\end{array}$ \\
\hline Responders & $0.40 \pm 0.18(121)$ & $0.94 \pm 0.55(19)^{*}$ & $0.45 \pm 0.33(116)$ \\
Nonresponders & $0.67 \pm 0.60(8)$ & $3.24 \pm 1.74(11)^{* *}$ & $0.84 \pm 1.20(32)$
\end{tabular}

Neurons are classified according to their abilities to respond to various GLU receptor agonists applied at varying times after toxic GLU pretreatment. Data are presented as mean $\pm \mathrm{SD}$ ( $N$ in parentheses).

${ }^{*} p<0.01$ compared to initial values with Dunnett's modified $t$ test comparing all later time points to initial values.

** $p<0.001$ compared to initial values with Dunnett's modified $t$ test comparing all later time points to initial values and $p<0.001$ compared to responders using Satterthwaite's $t$ test for unequal variances (Steel and Torrie, 1980).

bright appearance. Swollen neurons with a dull phase-bright or transparent phase-gray appearance were too fragile to survive the mechanical pressure of the patch pipette. All of the successfully sealed, slightly swollen neurons responded to pressure application of $100 \mu \mathrm{M}$ GLU with large inward currents (Fig. 7). These currents averaged $-420 \pm 178 \mathrm{pA}$ (mean $\pm \mathrm{SD} ; N=24$ ) at a holding potential of $-60 \mathrm{mV}$, or $-7.35 \pm 2.74 \mathrm{pA} / \mathrm{pS}$ when normalized to membrane capacitance. Neurons displayed healthy resting potentials $(-58.9 \pm 9.8 \mathrm{mV})$. Spontaneous excitatory and inhibitory postsynaptic currents, present on almost all cells, were noticeably less frequent than would be expected from a naive culture, reflecting the loss of many neurons. Recordings were generally limited to less than 10 min since these previously injured cells tended to swell rapidly once the whole-cell recording mode was established. In one experiment $6 \mathrm{hr}$ after toxic pretreatment, six out of six neurons responded to GLU in the presence of $20 \mu \mathrm{M}$ MK-801 with an average inward current amplitude of $-239 \pm 273 \mathrm{pA}$ (or $7.88 \pm 4.39 \mathrm{pA} / \mathrm{pS}$ ). Twentyfour hours after the same toxic pretreatment, six out of six neurons in a sister culture responded to GLU in the presence of $20 \mu \mathrm{M}$ CNQX $(-294 \pm 232 \mathrm{pA}$ or $9.09 \pm 5.84 \mathrm{pA} / \mathrm{pS})$. Thus, it appears that GLU receptors remain functional, even on morphologically compromised hippocampal neurons in the process of dying.

\section{Discussion}

This set of experiments illustrates the point that intracellular calcium levels are not permanently elevated following a transient toxic exposure to an excitotoxin. Following short GLU exposure, $\left[\mathrm{Ca}^{2+}\right]_{i}$ remained elevated for approximately half an hour, gradually returning to normal basal levels over the course of the next hour. Basal calcium levels were reestablished and maintaincd for up to $13 \mathrm{hr}$ following toxic insult. These results extend a similar observation of the recovery of basal calcium levels during $3 \mathrm{hr}$ of continuous monitoring following GLU exposure (Randall and Thayer, 1992). Surviving neurons were therefore capable of overcoming the massive calcium influx initiated by GLU receptor activation. Calcium buffering mechanisms were not totally compromised by the initial insult and were sufficiently active to restore and maintain resting calcium concentrations. Since intracellular energy metabolism is transiently elevated following GLU toxicity (Raley-Susman et al., 1992), the recovery of basal calcium levels may be attributable to overactive, energy-driven, calcium clearance mechanisms.

Recovery of resting calcium levels has been previously reported in paradigms where GLU agonists were applied for very brief periods (Furuya et al., 1989; Murphy et al., 1987) or to immature hippocampal cultures (Ogura et al., 1988; Wahl et al., 1989). In experiments employing a constant perfusion system for application of EAAs, $\left[\mathrm{Ca}^{2+}\right]_{i}$ have generally remained elevated (de Erausquin et al., 1990; Glaum et al., 1990; Dubinsky and Rothman, 1991). Under the latter conditions, $\left[\mathrm{Ca}^{2+}\right]_{i}$ was obscrved to increase without any appreciable recovery over the hour following toxic exposure (Dubinsky and Rothman, 1991). Occasionally, $\left[\mathrm{Ca}^{2+}\right]_{i}$ of individual cells was observed to decline slightly over this time period (J. M. Dubinsky, unpublished observations). This was in marked contrast to the present experiments, where $\left[\mathrm{Ca}^{2+}\right]_{i}$ returned to initial levels following an exposure paradigm that was toxic to sister cultures. In the previous perfusion experiments, the constant flow of fresh solution may have altered the glutamine/GLU balance normally maintained by the glial feeder layer (Rosenberg, 1991), preventing a timely recovery of $\left[\mathrm{Ca}^{2+}\right]_{i}$. Additionally, in many of the experiments in which $\left[\mathrm{Ca}^{2+}\right]_{i}$ remained elevated (Murphy et al., 1987; Ogura et al., 1988; de Erausquin et al., 1990; Glaum et al., 1990; Michaels and Rothman, 1990; Ciardo and Meldolesi, 1991; Dubinsky and Rothman, 1991), neurons were loaded with fura-2-AM for intervals ranging from $30 \mathrm{~min}$ to 1 hr. Under these conditions, high concentrations of fura- 2 may have accumulated intracellularly, perhaps competing with cellular buffering mechanisms, contributing to prolonged elevations in $\left[\mathrm{Ca}^{2+}\right]_{i}$ (Moore et al., 1990; Sala and Hernandez-Cruz,

TABLE 2. Occurrence of compromised morphology among neurons responding and failing to respond to EAA application

\begin{tabular}{|c|c|c|c|c|c|c|}
\hline & No pr & tment & $\begin{array}{l}\leq 1 \mathrm{hr} \\
\text { pretre }\end{array}$ & & $\begin{array}{l}>1 \mathrm{hr} \\
\text { pretrea }\end{array}$ & \\
\hline & Good & $\begin{array}{l}\text { Com- } \\
\text { promised }\end{array}$ & Good & $\begin{array}{l}\text { Com- } \\
\text { promised }\end{array}$ & Good & $\begin{array}{l}\text { Com- } \\
\text { promised }\end{array}$ \\
\hline Responders & 109 & 2 & 19 & 0 & 108 & 8 \\
\hline Nonresponders & 4 & 0 & 7 & $4^{*}$ & 18 & $14^{* *}$ \\
\hline
\end{tabular}

Neurons are classified according to the elapsed time following toxic GLU pretreatment.

* Significantly higher incidence than among responders, $p=0.01$ Fischer's Exact Probability Test.

** $p<0.001$. 
1990). In the present experiments, care was taken to limit the concentration of fura- 2 to prevent perturbing the processes being measured.

If the increases in $\left[\mathrm{Ca}^{2+}\right]_{i}$ trigger internal processes that lead to neuronal death, $\left[\mathrm{Ca}^{2+}\right]_{i}$ does not have to remain elevated continually for these events to occur. Considering that $85 \%$ of all neurons initially in the cultures were destined to die in the $24 \mathrm{hr}$ following GLU treatment, the majority of the neurons monitored in the present experiments would be expected to succumb eventually to excitotoxic cell death. A small number of neurons monitored at extended times did display elevated $\left[\mathrm{Ca}^{2+}\right]_{i}$. It is not known whether these neurons failed to recover from the first insult or whether their calcium levels spontaneously increased at a later time, perhaps consequent to membrane leakage prior to imminent death (Randall and Thayer, 1992). The exact sequence of intracellular events following GLU overstimulation leading to eventual neuronal death is not known. An initial elevation in $\left[\mathrm{Ca}^{2+}\right]_{i}$ is thought to be causative for subsequent calcium-mediated cytotoxic processes (Orrenius et al., 1989; Choi, 1990). Candidate destructive intracellular enzymes include calpain-induced cytoskeletal breakdown (Di Stasi et al., 1991; Johnson et al., 1991), phospholipase $A_{2}$-induced formation of arachidonic acid and metabolites (Barbour et al., 1989; Lazarewicz et al., 1990; Miller et al., 1992), membrane translocation of protein kinase C (Manev et al., 1990), and calcium-activated endonuclease destruction of cellular DNA (Orrenius et al., 1989). These processes all could be initiated during the period of elevated $\left[\mathrm{Ca}^{2+}\right]_{i}$ and proceed on toward eventual cytotoxicity even after calcium homeostasis has been reestablished.

Activation of non-NMDA receptors has been implicated in the delayed phase of GLU toxicity (Koh et al., 1990; Garthwaite and Garthwaite, 1991a,b). Prolonged elevation of extracellular GLU may occur as a result of failure and perhaps reversal of the GLU uptake system in neurons and astrocytes (Nicholls and Attwell, 1990). Long exposures to low doses of kainate or AMPA produce neuronal cell necrosis in both brain slices and culture preparations sensitive to extracellular calcium concentration (Garthwaite and Garthwaite, 1991a,b). It is hypothesized that a subclass of non-NMDA receptors permeable to calcium (Iino et al., 1990; Gilbertson et al., 1991) may be responsible for this (Garthwaite and Garthwaite, 1991b). In the paradigm employed in the present experiments, extracellular accumulation of endogenous GLU would be expected to stimulate these receptors continually and produce the delayed neuronal death. If nonNMDA receptor-stimulated $\mathrm{Ca}$ influx or release from intracellular stores were chronically and globally active, the resting calcium levels many hours after GLU exposure would be expected to be elevated. No significant increases were observed, indicating that such a mechanism must not be globally active in the hours following excitotoxic damage. Occasionally, neurons with greatly elevated $\left[\mathrm{Ca}^{2+}\right]_{i}$ were encountered, and these could represent a subpopulation receiving endogenous excitotoxic stimulation or rapid alterations in $\left[\mathrm{Ca}^{2+}\right]_{i}$ just prior to cell death. But the presence of healthy appearing neurons with normal calcium levels in close proximity suggests that very localized factors are involved, either failure of GLU uptake mechanisms (Nicholls and Attwell, 1990) or differences in receptor density among neighboring neurons.

Additionally, after recovering from the first excitotoxic increase in $\left[\mathrm{Ca}^{2+}\right]_{i}$, many hippocampal neurons were fully capable of responding a second time to a variety of GLU receptor agonists with a second rise in $\left[\mathrm{Ca}^{2+}\right]_{i}$. The initial toxic insult does

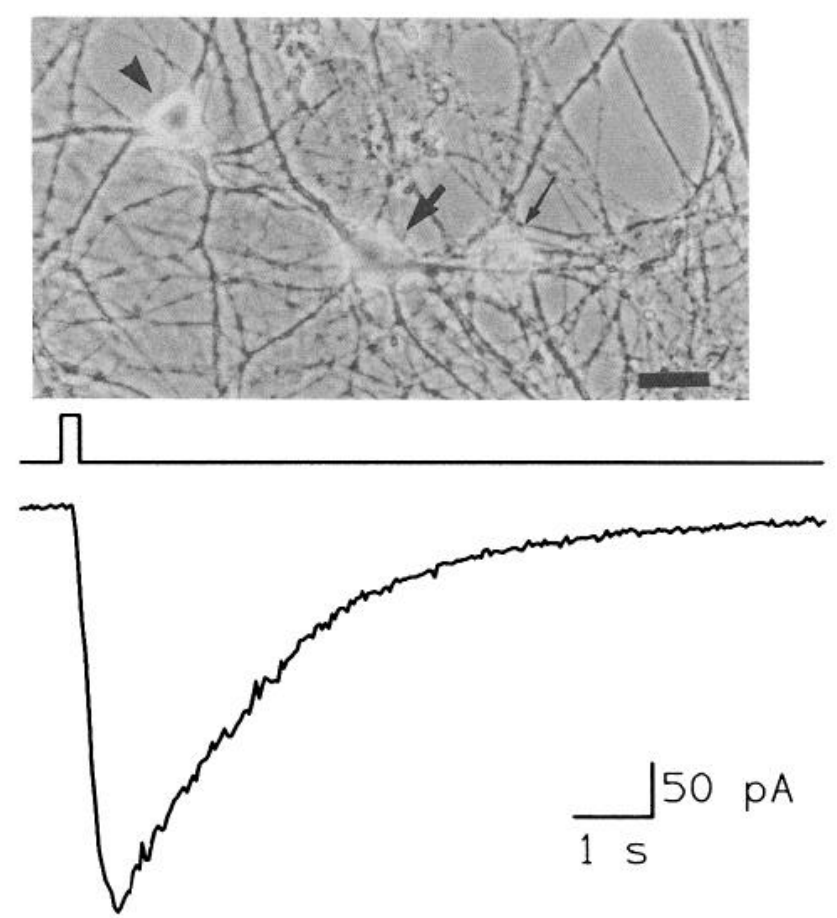

Figure 7. Electrophysiological response of morphologically compromised hippocampal neuron (thick arrow) surviving $6 \mathrm{hr}$ after GLU exposure. Phase-contrast photomicrograph illustrates a phase-bright, healthy-appearing neuron (arrowhead) and a transparent, extremely swollen neuron (thin arrow) in addition to the slightly swollen, transparent, yet still somewhat phase-bright neuron used for recordings. Bottom trace is current response to pressure application of $100 \mu \mathrm{M}$ GLU (top trace). Scale bar, $20 \mu \mathrm{m}$.

not leave most neurons refractory to additional stimulation. Thus, hippocampal neurons can sustain repeated insults and may become subject to cycles of damage that may be potentially more damaging than single insults. When basal calcium levels were still elevated following the first toxic exposure, a neuron was less likely to respond to the second application. Under these conditions, reopening of GLU channels may have served to keep $\left[\mathrm{Ca}^{2+}\right]_{i}$ elevated, masking both recovery and the continued ability to respond.

The absence of a second calcium response among one-quarter of neurons is puzzling since it is unlikely that such a large subpopulation would lack calcium-permeable GLU channels. Initial fluorescence emissions at $380 \mathrm{~nm}$ were within normal range, and the ratio measurements were not abnormally low as might be expected if these neurons were unable to cleave the acetylmethyl ester from the fura-2-AM (Moore et al., 1990; Roe et al., 1990). Similarly, autofluorescence from endogenous NADH (Uematsu et al., 1991) among neurons unable to load any fura2-AM was too dim to account for the observed signal. A portion $(41.9 \%)$ of these nonresponders evidenced signs of morphological deterioration and impending cell death and might be expected to lack a calcium response, but over half $(58.1 \%)$ of the nonresponders appeared healthy. Nonresponders were seen among $6 \%$ of neurons in naive cultures receiving a first toxic exposure. If responding neurons preferentially succumbed to delayed cell death during the time period of these experiments, then the proportion of nonresponding neurons might consequently increase. Alternatively, the nonresponders could represent neurons with a very fast transient calcium response that returned to basal values before the first measurement was made 
at $1 \mathrm{~min}$ following EAA application. This, however, seems unlikely since in most experiments, agonist was present for prolonged periods and plateau responses were evident even for metabotropic receptor activation (Furuya et al., 1989; Murphy and Miller, 1989a; Glaum et al., 1990). Other possible explanations could involve some cytoplasmic mechanisms to reduce calcium influx through NMDA receptors, either by receptor oxidation (Aizenman et al., 1990) or by blockage by an endogenous metal ion (Eimerl and Schramm, 1992).

In contrast with the calcium measurements, electrophysiological recordings from neurons surviving a toxic GLU application showed that all neurons healthy enough to have an intact membrane were still able to respond to GLU. Selective death of neurons with high GLU sensitivity should have increased the percentage of neurons lacking an electrophysiological response equivalently. Perhaps the nonresponding neurons represent a subpopulation in the first stages of the cell death process, prior to morphological deterioration. In this case, the electrophysiological experiments should have encountered this population since only morphologically compromised neurons were chosen. A resolution between the electrophysiological and fluorescent measurements could possibly be achieved if some neurons experienced cytoplasmic alterations in viscosity or biochemistry that reduced the sensitivity of the foreign fura-2 molecule ( $\mathrm{Di}$ Virgilio et al., 1990; Poenie, 1990; Roe et al., 1990; Owen, 1991).

While morphologically deteriorating neurons were more likely to lack a calcium response to GLU, this was not always the case. The lack of a perfect correlation between morphological deterioration and inability to respond a second time to GLU may indicate that these are independent events, both triggered by the initial excitotoxic application. Subsequent cytoplasmic processes could result in both of these intermediate outcomes during the transit to eventual cellular death. Following excitotoxic exposure, $\left[\mathrm{Ca}^{2+}\right]_{i}$ rose and transiently remained elevated. Although the subsequent recovery of basal calcium levels does not ensure neuronal survival, it is perhaps indicative of a cell struggling to regain its homeostatic equilibrium. In this condition, the neurons may be especially vulnerable to further excitotoxic insult.

\section{References}

Aizenman E, Hartnett KA, Reynolds IJ (1990) Oxygen free radicals regulate NMDA receptor function via a redox modulatory site. Neuron 5:841-846.

Barbour B, Szatkowski M, Ingledew N, Attwell D (1989) Arachidonic acid induces a prolonged inhibition of glutamate uptake into glial cells. Nature 342:918-920.

Choi DW (1990) Cerebral hypoxia: some new approaches and unanswered questions. J Neurosci 10:2493-2501.

Ciardo A, Meldolesi J (1991) Regulation of intracellular calcium in cerebellar granule neurons: effects of depolarization and of glutamatergic and cholinergic stimulation. J Neurochem 56:184-191.

Connor JA, Wadman WJ, Hockberger PE, Wong RKS (1988) Sustained dendritic gradients of $\mathrm{Ca}^{2+}$ induced by excitatory amino acids in CA1 hippocampal neurons. Science 240:649-653.

de Erausquin GA, Manev H, Guidotti A, Costa E, Brooker G (1990) Gangliosides normalize distorted single-cell intracellular free $\mathrm{Ca}^{2+}$ dynamics after toxic doses of glutamate in cerebellar granule cells. Proc Natl Acad Sci USA 87:8017-8021.

Di Stasi AMM, Gallo V, Ceccarini M, Petrucci TC (1991) Neuronal fodrin proteolysis occurs independently of excitatory amino acidinduced neurotoxicity. Neuron 6:445-454.

Di Virgilio F, Steinberg TH, Silverstein SC (1990) Inhibition of fura-2 sequestration and secretion with organic anion transport blockers. Cell Calcium 11:57-62.

Dubinsky JM (1989) Development of inhibitory synapses among striatal neurons in vitro. J Neurosci 9:3955-3965.
Dubinsky JM, Rothman SM (1991) Intracellular calcium concentrations during "chemical hypoxia" and excitotoxic neuronal injury. J Neurosci 11:2545-2551

Eimerl S, Schramm M (1992) An endogenous metal appears to regulate NMDA receptor mediated ${ }^{45} \mathrm{Ca}$ influx and toxicity in cultured cerebellar granule cells. Neurosci Lett 137:198-202.

Finkbeiner S Stevens CF (1988) Applications of quantitative measurements for assessing glutamate neurotoxicity. Proc Natl Acad Sci USA 85:4071-4074.

Furuya S, Ohmori H, Shigemoto T, Sugiyama H (1989) Intracellular calcium mobilization triggered by a glutamate receptor in rat cultured hippocampal cells. J Physiol (Lond) 414:539-548.

Garthwaite G, Garthwaite J (1986) Neurotoxicity of excitatory amino acid receptor agonists in rat cerebellar slices: dependence on calcium concentration. Neurosci Lett 66:193-198.

Garthwaite G, Garthwaite J (1991a) AMPA neurotoxicity in rat cerebellar and hippocampal slices: histological evidence for three mechanisms. Eur J Neurosci 3:715-728.

Garthwaite G, Garthwaite J (1991b) Mechanisms of AMPA neurotoxicity in rat brain slices. Eur $J$ Neurosci 3:729-736.

Gilbertson TA, Scobey R, Wilson M (1991) Permeation of calcium ions through non-NMDA glutamate channels in retinal bipolar cells. Science 251:1613-1615.

Glaum SR, Scholz WK, Miller RJ (1990) Acute- and long-term glutamate-mediated regulation of $\left[\mathrm{Ca}^{++}\right] \mathrm{i}$ in rat hippocampal pyramidal neurons in vitro. J Pharmacol Exp Ther 253:1293-1302.

Grynkiewicz G, Poenie M, Tsien RY (1985) A new generation of $\mathrm{Ca}^{2+}$ indicators with greatly improved fluorescence properties. J Biol Chem 260:3440-3450.

Hamill OP, Marty A, Neher E, Sakmann B, Sigworth FJ (1981) Improved patch-clamp techniques for high-resolution current recording from cells and cell-free membrane patches. Pfluegers Arch 391:85100.

Hartley DM, Choi DW (1989) Delayed rescue of $N$-methyl-D-aspartate receptor-mediated neuronal injury in cortical culture. J Pharmacol Exp Ther 250:752-758.

Iino M, Ozawa S, Tsuzuki K (1990) Permeation of calcium through excitatory amino acid receptor channels in cultured rat hippocampal neurones. J Physiol (Lond) 424:151-165.

Johnson GW, Litersky J, Jope RS (1991) Degradation of microtubuleassociated protein 2 and brain spectrin by calpain: a comparative study. J Neurochem 56:1630-1638.

Koh JY, Goldberg MP, Hartley DM, Choi DW (1990) Non-NMDA receptor-mediated neurotoxicity in cortical culture. J Neurosci 10: 693-705.

Lanthorn TH, Hood WF, Watson GB, Compton RP, Rader RK, Gaoni Y, Monahan JB (1990) cis-2,4-Methanoglutamate is a potent and selective $N$-methyl-D-aspartate receptor agonist. Eur J Pharmacol 182: 397-404.

Lazarewicz JW, Wroblewski JT, Costa E (1990) N-Methyl-D-aspartate-sensitive glutamate receptors induce calcium-mediated arachidonic acid release in primary cultures of cerebellar granule cells. J Neurochem 55:1875-1881.

MacDermott AB, Mayer ML, Westbrook GL, Smith SJ, Barker JL (1986) NMDA-receptor activation increases cytoplasmic calcium concentration in cultured spinal cord neurones. Nature 321:519-522.

Manev H, Favaron M, Guidotti A, Costa E (1989) Delayed increase of $\mathrm{Ca}^{2+}$ influx elicited by glutamate: role in neuronal death. Mol Pharmacol 36:106-112.

Manev H, Favaron M, Vicini S, Guidotti A, Costa E (1990) Glutamate-induced neuronal death in primary cultures of cerebellar granule cells: protection by synthetic derivatives of endogenous sphingolipids. J Pharmacol Exp Ther 252:419-427.

Michaels R, Rothman S (1990) Glutamate neurotoxicity in vitro: antagonist pharmacology and intracellular calcium concentrations. $J$ Neurosci 10:283-292.

Miller B, Sarantis M, Traynelis SF, Attwell D (1992) Potentiation of NMDA receptor currents by arachidonic acid. Nature 355:722-725.

Moore EDW, Becker PL, Fogarty KE, Williams DA, Fay FS (1990) $\mathrm{Ca}^{2+}$ imaging in single living cells: theoretical and practical issues. Cell Calcium 11:157-179.

Murphy SN, Miller RJ (1989a) Two distinct quisqualate receptors regulate $\mathrm{Ca}^{2+}$ homeostasis in hippocampal neurons in vitro. Mol Pharmacol 35:671-680.

Murphy SN, Miller RJ (1989b) Regulation of $\mathrm{Ca}^{++}$influx into striatal neurons by kainic acid. J Pharmacol Exp Ther 249:184-193.

Murphy SN, Thayer SA, Miller RJ (1987) The effects of excitatory 
The Journal of Neuroscience, February 1993, 13(2) 631

amino acids on intracellular calcium in single mouse striatal neurons in vito. J Neurosci 7:4145-4158.

Nichols D, Attwell D (1990) The release and uptake of excitatory amino acids. Trends Pharmacol Sci 11:462-468.

Ogura A, Miyamoto M, Kudo Y (1988) Neuronal death in vitro: parallelism between survivability of hippocampal neurons and surtaine elevation of cytosolic $\mathrm{Ca}^{2+}$ after exposure to glutamate receptor agonist. Exp Brain Res 73:447-458.

Orrenius S, McConkey DJ, Bellomo G, Nicotera P (1989) Role of $\mathrm{Ca}^{2+}$ in toxic cell killing. Trends Pharmacol Sci 10:281-285.

Owen CS (1991) Spectra of intracellular fura-2. Cell Calcium 12:385393.

Poenie M (1990) Alteration of intracellular fura-2 fluorescence by viscosity: a simple correction. Cell Calcium 11:85-91.

Raley-Susman KM, Miller KR, Owicki JC, Sapolsky RM (1992) Fffacts of excitotoxin exposure on metabolic rate of primary hippocampal cultures: application of silicon microphysiometry to neurobiology. J Neurosci 12:773-780.

Randall RD, Thayer SA (1992) Glutamate-induced calcium transient triggers delayed calcium overload and neurotoxicity in rat hippocampal neurons. J Neurosci 12:1882-1895.

Roe MW, Lemasters JJ, Herman B (1990) Assessment of fura-2 for measurements of cytosolic free calcium. Cell Calcium 11:63-73.
Rosenberg P (1991) Accumulation of extracellular glutamate and newronal death in astrocyte-poor cortical cultures exposed to glutamine. Glia 4:91-100.

Rothman SM, Thurston JH, Hauhart RE (1987) Delayed neurotoxicily of excitatory amino acids in vito. Neuroscience 22:471-480.

Sal F, Hernandez-Cruz A (1990) Calcium diffusion modeling in a spherical neuron. Biophys J 57:313-324.

Siesjo B (1989) Calcium and cell death. Magnesium 8:223-237.

Steel RGD, Terrie JH (1980) Principles and procedures of statistics, a biometrical approach. New York: McGraw Hill.

Uematsu D, Greenberg JH, Araki N, Reivich M (1991) Mechanism underlying protective effect of MK-801 against NMDA-induced neoronal injury in vive. J Cere Blood Flow Metal 11:779-785.

Wahl P, Schousboe A, Honor T, Drejer J (1989) Glutamate-induced increase in intracellular $\mathrm{Ca}^{2+}$ in cerebral cortex neurons is transient in immature cells but permanent in mature cells. J Neurochem 53: 1316-1319.

Yamada KA, Dubinsky JM, Rothman SM (1989) Quantitative physbiological characterization of a quinoxalinedione non-NMDA receptor antagonist. J Neurosci 9:3230-3236.

Yoon KW, Rothman SM (1991) Adenosine inhibits excitatory but not inhibitory synaptic transmission in the hippocampus. J Neurosci 11:1375-1380. 